\title{
Potências e limites no cotidiano da formação acadêmica no cuidado à saúde da pessoa surda
}

\author{
Potentialities and limits in the everyday life of undergradute training in health care for deaf people \\ Potencias y límites en el curso diario de la formación académica en la atención médica para personas \\ sordas
}

\author{
Lucas Andreolli Bernardo ${ }^{1}$ \\ Adriana Dutra Tholl ${ }^{2}$ (b) \\ Rosane Gonçalves Nitschke² (1) \\ Selma Maria da Fonseca Viegas ${ }^{3}$ (D) \\ Soraia Dornelles Schoeller ${ }^{2}$ (B) \\ Maria Ligia dos Reis Bellaguarda ${ }^{2}$ (1) \\ Daniela Priscila Oliveira do Vale Tafner ${ }^{4}$ (])
}

1. Prefeitura Municipal de Bombinhas.

Bombinhas, SC, Brasil.

2. Universidade Federal de Santa Catarina.

Florianópolis, SC, Brasil.

3. Universidade Federal de São João del-Rei, Campus Centro-Oeste. São João del-Rei, MG, Brasil.

4. Universidade Federal de Santa Catarina, Programa de Pós-Graduação de Enfermagem. Florianópolis, SC, Brasil.

Autor correspondente:

Lucas Andreolli Bernardo.

E-mail: lucas_a.bernardo@hotmail.com.

Recebido em 25/08/2020.

Aprovado em 19/11/2020

DOl:https://doi.org/10.1590/2177-9465-EAN-2020-0341

\section{REsUMO}

Objetivo: compreender as potências e os limites no cotidiano da formação dos estudantes de graduação no cuidado à saúde da pessoa surda. Método: trata-se de um estudo qualitativo e interpretativo, fundamentado na Sociologia Compreensiva e do Cotidiano, envolvendo 18 estudantes de uma universidade federal do Sul do Brasil dos cursos de graduação em Enfermagem, Farmácia, Fonoaudiologia, Medicina, Nutrição, Odontologia e Psicologia. As fontes de evidências foram entrevistas individuais desenvolvidas no período de outubro a novembro de 2019. A análise dos dados envolveu a análise preliminar, a ordenação, as ligações-chave, a codificação e a categorização. Resultados: as potências no cotidiano da formação dos estudantes no cuidado à saúde da pessoa surda mostram-se na comunicação instituinte, na tecnossocialidade no cuidado e no falar Libras e poder integrar-se à comunidade surda. Os limites mostram-se nos modelos e nas práticas formativas não inclusivas, na impessoalidade da interpretação e na falta de especificidade técnica na disciplina de Libras. Conclusão e implicações para a prática: conclui-se que há a necessidade de se refletir sobre os currículos dos cursos da área da saúde, proporcionado a inclusão do cuidado à saúde da pessoa surda, a fim de capacitar os estudantes para a atuação nos diferentes níveis de complexidade.

Palavras-chave Surdez; Pessoas com Deficiência Auditiva; Estudantes; Atividades Cotidianas; Assistência à Saúde.

\section{Abstract}

Objective: to understand the potencialities and the limits in the daily training of undergraduate students in the health care of the deaf person. Method: it is a qualitative and interpretative study, based on Comprehensive and Daily Sociology, involving 18 students from a federal university in the South of Brazil of the undergraduate courses in Nursing, Pharmacy, Speech Therapy, Medicine, Nutrition, Dentistry and Psychology. The sources of evidence were individual interviews developed from October to November 2019. The data analysis involved preliminary analysis, ordering, key links, coding and categorization. Results: the potencialities in the daily training of students in health care of the deaf person are shown in the communication institute, the techno-sociality in care and the communicating in Libras and being able to integrate with the deaf community. The limits are shown in the models and training practices not inclusive, the impersonality of interpretation and lack of technical specificity in the Libras (Brazilian sign language) discipline. Conclusion and implications for practice: it is concluded that there is a need to reflect on the curricula of health courses, providing the inclusion of health care for deaf people in order to enable students to act at different levels of complexity.

Keywords: Deafness; Hearing-Impaired people; Students; Everyday Life Activities; Health Care.

\section{Resumen}

Objetivo: comprender las potencias y límites en la formación diaria de estudiantes de pregrado en atención a la salud de personas sordas. Método: se trata de un estudio cualitativo e interpretativo, basado en Sociología Integral y Cotidiana, que involucró a 18 estudiantes de una universidad federal del Sur de Brasil, de cursos de licenciatura en Enfermería; Farmacia; Terapia del lenguaje; Medicina; Nutrición; Odontología y Psicología. Las fuentes de evidencia fueron entrevistas individuales, desarrolladas de octubre a noviembre de 2019. El análisis de datos ha involucrado el análisis preliminar, el ordenamiento, las llamadas clave, la codificación y la categorización. Resultados: las potencias en la formación diaria de los estudiantes en la atención de la salud de los sordos se manifiestan en la instauración de la comunicación, en la tecnosocialidad en la atención y en hablar Libras y la capacidad de integrarse con la comunidad sorda. Los límites se muestran en los modelos y en las prácticas de entrenamiento no inclusivo, en la impersonalidad de la interpretación y en la falta de especificidad técnica en la asignatura de Libra. Conclusión e implicaciones para la práctica: se concluye que existe la necesidad de reflexionar sobre los planes de estudio de los cursos de salud, proporcionando la inclusión de la atención de la salud a las personas sordas, con el fin de capacitar a los estudiantes para trabajar en los diferentes niveles de complejidad.

Palabras clave: Sordera; Educación de Personas con Discapacidad Auditiva; Estudiantes; Actividades Cotidianas; Prestación de Atención de Salud 


\section{INTRODUÇÃO}

A população surda não tem suas necessidades de saúde atendidas. Um dos fatores responsáveis é que a pessoa surda tem menos oportunidades de acessar informações sobre prevenção, tratamento ou assistência à saúde. Intervenções para reduzir essa exclusão e garantir que estes tenham seus direitos de acesso aos serviços de saúde ainda são necessárias. ${ }^{1}$

Segundo o Instituto Brasileiro de Geografia e Estatística² (IBGE), no Brasil, há cerca 9,7 milhões de pessoas com deficiência auditiva ( $5,1 \%$ da população do país) e, segundo a Organização Mundial da Saúde (OMS), em 2018, havia aproximadamente 466 milhões de pessoas, $6,1 \%$ da população mundial, com algum grau de surdez. ${ }^{3}$

A qualidade de vida relacionada à saúde, para quem vive com a surdez, ainda precisa ser percebida como um aspecto de grande importância na sociedade contemporânea, visto que as pessoas surdas ainda são excluídas nas políticas de saúde. ${ }^{4}$

A Lei $n^{\circ}$ 10.436, de 24 d e abril de 2002, reconhece a Língua Brasileira de Sinais (Libras) como a segunda língua oficial do país e decreta que as instituições públicas e as empresas de serviços de assistência à saúde devem garantir o atendimento e o tratamento adequados às pessoas com surdez, de acordo com as normas legais em vigor. ${ }^{5}$

Considerar os determinantes da qualidade de vida, em relação à saúde das pessoas com surdez, é decisivo para que as condições de saúde dessa população possam ser melhoradas. ${ }^{4}$

A Portaria $n^{\circ}$ 2.073, de setembro de 2004, garante a ampla cobertura no atendimento a pessoas com surdez no Brasil, sustentando a universalidade do acesso, a equidade, a integralidade e o controle social da saúde auditiva. ${ }^{6}$ No entanto, a ausência de comunicação efetiva entre o profissional de saúde e a pessoa surda, a necessidade de intermediação pelo acompanhante/intérprete e o despreparo dos profissionais no cuidado à pessoa surda fazem com que o direito à saúde não seja contemplado. ${ }^{7}$ Nesta corrente, "cuidar é mais que um ato; é uma atitude. Portanto, abrange mais que um momento de atenção. Representa uma atitude de ocupação, preocupação, de responsabilização e de envolvimento afetivo com o outro"8:12.

Os currículos dos cursos que formam profissionais da saúde não envolvem competências e habilidades relacionadas ao cuidado à saúde da pessoa surda. Não são capacitados para prestar assistência específica a esta população. ${ }^{9}$ Os profissionais de saúde, na prática, sentem-se incapazes, impotentes, inseguros e constrangidos devido à dificuldade de comunicação pela falta de preparo e por não saberem a Libras. ${ }^{10}$ Neste sentido, o estudo justifica-se pela evidente necessidade de atribuir, à formação dos estudantes de graduação, as competências necessárias para o cotidiano do cuidado à saúde da pessoa surda nos diferentes contextos, visto que, durante a formação dos estudantes, não há um cenário de prática específico para esta clientela, mas a pessoa surda se faz presente nos diferentes contextos de cuidado à saúde.

Compreende-se por cotidiano a "maneira de viver dos seres humanos que se mostra no dia a dia, expresso por suas interações, crenças, valores, símbolos, significados, imagens e imaginário, que vão delineando seu processo de viver, num movimento de ser saudável e adoecer, pontuando seu ciclo vital. Esse percurso pelo ciclo vital tem uma determinada cadência que caracteriza nossa maneira de viver, influenciada tanto pelo dever ser, como pelas necessidades e desejos do dia a dia, que se domina como ritmo de vida e do viver"11:8.

Trata-se de um estudo de relevância temática, podendo contribuir para a formação acadêmica de graduação no cuidado à saúde de pessoas surdas nos diferentes contextos da saúde e, consequentemente, beneficiar a população surda, pois contribui para uma atenção à saúde mais inclusiva. Diante disso, o objetivo do estudo é compreender o cotidiano da formação acadêmica de estudantes de graduação no cuidado à saúde da pessoa surda nos ambientes de saúde.

\section{MÉTODO}

Elegeu-se, para fundamentar este estudo, a Sociologia Compreensiva e do Cotidiano, ${ }^{12}$ considerando que a surdez é um fenômeno que afeta o ser humano na sua multidimensionalidade, especialmente, em sua condição física, psíquica, social, e, especificamente, no seu acesso à saúde, que reflete no seu dia a dia e na sua maneira de viver e conviver.

Trata-se de um estudo qualitativo e interpretativo tendo como cenário uma universidade federal do Sul do Brasil localizada na cidade de Florianópolis - Santa Catarina. A definição do cenário de estudo ocorreu devido à instituição ofertar cursos de graduação da área da saúde. Participaram do estudo 18 estudantes de cursos de graduação, que já haviam realizado o cuidado à saúde da pessoa surda, sendo: quatro estudantes do curso de Enfermagem; quatro de Farmácia; quatro de Fonoaudiologia; três de Medicina; um de Nutrição; um de Odontologia e um de Psicologia.

O convite para a participação no estudo foi realizado, primeiramente, aos estudantes do curso de Enfermagem, da 9ำ fase, em sala de aula, pelo pesquisador principal. A partir do primeiro contato com os estudantes dessa turma, optou-se pela técnica "bola de neve" para a coleta de dados ${ }^{13}$ em que os próprios participantes indicaram outros novos participantes com características e perfil desejados para a pesquisa.

Consideraram-se como critérios de inclusão dos participantes: ter, pelo menos, 18 anos; ser estudante dos cursos de graduação em Educação Física (bacharel), Enfermagem, Farmácia, Fonoaudiologia, Medicina, Nutrição, Odontologia, Psicologia e Serviço Social e que já ter prestado cuidado à saúde da pessoa surda nos ambientes de saúde, em algum momento, durante a graduação. Como critérios de exclusão, consideraram-se os alunos que estavam com trancamento da matrícula e os que não haviam realizado cuidado à saúde da pessoa surda. Ressalta-se que, nos cursos de Educação Física (bacharel) e Serviço Social, não foram encontrados estudantes que tivessem prestado cuidado à saúde da pessoa surda.

A coleta de dados foi realizada pelo autor principal do estudo, após a assinatura do Termo de Consentimento Livre e 
Esclarecido (TCLE) pelos participantes, no período entre outubro e novembro de 2019. Foram realizadas 18 entrevistas guiadas por um roteiro semiestruturado, elaborado pelo autor, baseado em duas questões norteadoras: "Quais as facilidades e as dificuldades no cuidado à saúde da pessoa surda?" e "Durante a sua formação acadêmica, você teve algum preparo para o cuidado à saúde da pessoa surda nos ambientes de saúde?". A suspensão da inclusão de novos participantes deu-se quando os dados coletados se mostraram repetitivos, determinando, assim, que os dados primários foram suficientes para alcançar os objetivos propostos e compreender o objeto em estudo.

As entrevistas foram audiogravadas, em profundidade, em local de preferência dos participantes, com uma duração média de 40 minutos, sendo posteriormente transcritas na íntegra e realizada a pré-análise. Como método de análise, utilizou-se o modelo de Análise de Conteúdo Temática, ${ }^{14}$ considerando as seguintes fases: pré-análise; exploração do material; tratamento dos resultados; inferência e interpretação.

A pesquisa foi desenvolvida após a aprovação pelo Comitê de Ética e Pesquisa, em setembro de 2019, sob Parecer de $\mathrm{n}^{\circ}$ 3.631.821, e seguiu os preceitos éticos referentes à pesquisa $e$ ao cuidado com seres humanos. Para a garantia do anonimato dos participantes, foi utilizada a letra "A", de acadêmico, seguida pela letra inicial do curso e do número da ordem das entrevistas.

\section{RESULTADOS}

Dentre os participantes da pesquisa, quatro acadêmicos são da Enfermagem, quatro, da Farmácia, quatro, da Fonoaudiologia, três, da Medicina, um, da Nutrição e um, da Odontologia, totalizando 18 estudantes. A faixa etária dos acadêmicos variou de 21 a 27 anos, sendo 12 do sexo feminino e seis do sexo masculino.

A aproximação com o cotidiano e com as vivências dos acadêmicos possibilitou a compreensão das potências e dos limites no cotidiano da formação de graduandos para o cuidado à saúde da pessoa surda. Os resultados são apresentados em duas categorias: Potências no cotidiano da formação de estudantes no cuidado à saúde da pessoa surda e Limites no cotidiano da formação de estudantes no cuidado à saúde da pessoa surda.

\section{Potências no cotidiano da formação de estudantes no cuidado à saúde da pessoa surda}

Na busca pela integralidade do cuidado à saúde da pessoa surda, os acadêmicos utilizam da comunicação instituinte, representada pela comunicação da escrita, da mímica, dos gestos, do desenho e da fala pausada, para possibilitar o acesso à saúde.

\section{Ele escrevia e eu escrevia no papel também [...]. (AM11)}

[...] ela (pessoa surda) foi lendo e eu, gesticulando e ela, respondendo no papelzinho para mim [...]. (AFC14)

[...] você tem que falar calmo, falar pausadamente, articular muito bem, para ele conseguir fazer a leitura labial. (AF5)
[...] os desenhos que eu fiz sobre as doses e para perguntar sobre as sobras de medicamentos [...]. (AFC13)

O uso de Tecnologias da Informação e Comunicação (TICs) configura-se como um meio de interação interpessoal, facilitando o acesso à saúde e a inclusão social da pessoa surda.

Eu ainda uso alguns aplicativos [...] para me comunicar com eles e me lembrar de alguns sinais. (AE16)

Para os graduandos, comunicar-se em Libras é uma condição essencial para o cuidado à saúde da pessoa surda pela possibilidade de interação e de resolução das suas necessidades.

Libras é o ponto principal para atender à sua necessidade; se a gente não tem a Libras, a gente não consegue trabalhar no contexto da criança surda. (AF12)

Durante a graduação, eu fiz o curso básico de Libras e isso me ajudou muito a resolver a necessidade daquela família. Eu era a única pessoa que conseguia se comunicar com as crianças diretamente, não tendo que falar com os pais [...]. (AE16)

Mesmo que a comunicação em Libras não seja fluente entre a pessoa surda e o acadêmico, a possibilidade de ser ouvida e ser compreendida em suas necessidades possibilita uma comunicação interpessoal mais afetiva, portanto, efetiva.

[...] eles se disponibilizam bastante para fazer você entender, eles têm bastante paciência. Então, eu vi que só de você [...] se mostrar "eu quero te ouvir, eu quero te entender"já deu para gente se comunicar bem [...]. (AP6)

[...] a paciente era muito compreensiva e calma. Porque ela estava feliz de poder se comunicar, então, ela tinha toda a paciência de repetir o gesto ou de soletrar se a gente não entendesse, tentar falar de alguma outra forma, então, isso foi muito bom. (AE17)

Integrar-se à comunidade surda é compreender o cotidiano das pessoas nessa condição. Para os acadêmicos, o contato com a pessoa surda ajudou-os na compreensão da dinâmica do processo de viver e da cultura surda. Esse contato diminuiu o distanciamento imposto pelas barreiras da comunicação, possibilitando um cuidado mais qualificado.

Hoje, eu tenho bastante facilidade porque eu já peguei o jeito dele, até na oralidade dele, peguei um jeitinho [...]e, nas primeiras sessões, era só escrita para um entender o outro. (AF3)

[...] estar imerso na comunidade surda, [...] dentro do contexto deles e trazer isso para a prática clínica nos aproxima. (AF12) 
Cotidiano de estudantes no cuidado de surdos

Bernardo LA, Tholl AD, Nitschke RG, Viegas SMF, Schoeller SD, Bellaguarda MLR, Tafner DPOV

[...] ter esse contato com a comunidade (surda) e com os professores [...] trouxe essa aproximação, de poder ir lá e perguntar quais são os termos técnicos. (AE17)

[...] com certeza, essas experiências (conhecer a comunidade surda) que eu tive ajudaram bastante. (AF18)

O acadêmico procura aprender Libras por afinidade pela área ou pela percepção da necessidade em aprender a partir do primeiro contato, visando à integralidade do cuidado à saúde da pessoa surda.

[...] não conhecia a parte da surdez, aí, eu pensei: "ah, pra acrescentar, vou fazer a disciplina de Libras", só que eu acabei gostando muito [...] e acabei focando na surdez e Libras. Então, foi bem por conta própria, fui correndo atrás. (AP6)

[...] teve muito impacto nas minhas outras colegas, depois que tiveram a experiência de estar junto com a gente ali na sala e tipo: "ah, agora eu vou buscar por que, né?". (AE17)

\section{Limites no cotidiano da formação de estudantes no cuidado à saúde da pessoa surda}

Na ótica dos acadêmicos, o modelo de formação é insuficiente para atender às necessidades da comunidade surda, que tem seus direitos de acesso à saúde negligenciados pela falta de comunicação adequada e satisfatória nos ambientes em saúde.

[...] eu acho que ele entendeu o básico. Não foi do jeito que deveria ter sido, se fosse uma consulta que tivesse uma comunicação mais efetiva. (AM11)

É a número um, é a comunicação. E, a partir da falta de comunicação, tudo se dificulta, né? (AM4)

Acho que o limite é realmente entender o que ele está querendo falar [...] a dificuldade é a gente dar instruções depois do atendimento. (AO9)

Eu acho que, de forma geral, o curso (graduação) tem uma dificuldade muito grande em competência de habilidade em comunicação e competências culturais. Porque você atende pessoas que vão além do teu nicho cultural. Então, no caso, a comunidade surda, isso acaba se aplicando bem porque você não consegue nem se comunicar, nem compreender a cultura que está por trás daquela pessoa. (AM7)

Os acadêmicos, em tempos pós-modernos, têm sede do infinito, buscam modelos e práticas formativas que deem respostas às suas inquietações, já não se contentam mais com a educação tradicional, buscam coerência, elaboram-se a partir da multiplicidade e da diversidade cultural nas experiências vividas.

A gente tem uma disciplina obrigatória, que é Psicologia e pessoas com deficiência [...], a gente teve uma aula sobre surdez, e aífoi isso, se você quiser aprender Libras, você vai correr atrás. [...] como que eu faço? Não tem nem pesquisa da Psicologia em relação à pessoa surda [...]. (AP6)

Infelizmente não. A gente não tem nenhuma matéria obrigatória para dar uma preparação para atender essa população. (AFC13)

[...] a gente tem várias aulas de comunicação com o paciente, tem muitas. Mas nunca foi tocado no assunto (comunicação com a pessoa surda) [...]. (AM11)

Foram apontadas, como um limite na formação para o cuidado à saúde da pessoa surda, a fraca mobilização para que os estudantes cursem a disciplina optativa de Libras e a falta de reflexão sobre o processo comunicacional com a pessoa surda nos ambientes da saúde. Assim, a necessidade de falar Libras torna-se uma necessidade quando os estudantes se deparam com a pessoa surda nos contextos da saúde e não se tem a competência para o cuidado com a comunicação efetiva.

[...] eu nunca tinha pensado que eu poderia atender uma pessoa surda até atender uma pessoa surda. Então, esse é até um grande limite, falta de exemplo dentro da graduação. (AE1)

[...] o preparo dos professores também motiva os alunos. (AE17)

[... ] eu vejo muito que o pessoal, quando faz a disciplina (Libras), acha super legal, se empolga, mas faz a disciplina de um semestre. E como o curso não tem um professor que fale sobre isso, o pessoal faz a disciplina e esquece. (AP6)

[...] a gente tem a optativa e ninguém fala da importância para usar. Só está ali ofertada. Mas ninguém toca no assunto para fazer a optativa. (AFC15)

[...] os professores, em si, dizem, de uma forma geral, tem que incluir todas as comunidades, só que não tem nenhuma matéria obrigatória de Libras e nenhum professor fala abertamente sobre isso em sala. Não é inserida a comunidade surda no nosso curso [...] é bem complicado porque eles dizem que tem que incluir, mas eles não mostram como incluir. (AFC14)

A tradução pelo intérprete no cuidado à saúde da pessoa surda pode caracterizar-se, na percepção dos acadêmicos, como uma prática impessoal, considerando que, em dado momento, o intérprete pode não expressar o verdadeiro sentimento/ necessidade da pessoa, tornando-a passiva no processo saúdedoença. A tradução pelo intérprete pode ainda se configurar como uma prática pouco sigilosa pela possibilidade de o intérprete ser conhecido da comunidade surda, comprometendo o sigilo profissional. 
[...] em relação ao sigilo profissional, ao ter o intérprete da comunidade surda, acaba que, às vezes, é um conhecido da pessoa, [...] tem algumas situações que fica um pouquinho mais delicada. (AF5)

A tradução, pelo intérprete, eu acho que diminui a autonomia (da pessoa com surdez) porque prende a interpretação (do intérprete) e que não necessariamente reflete o que o paciente está querendo se expressar. (AM7)

A disciplina básica de Libras, isolada da vivência técnica dos acadêmicos, não é vista por eles como suficiente para atender às necessidades de saúde da pessoa surda. Na área da saúde, é necessário conhecer os sinais dos termos técnicos e específicos para se fazer entender e compartilhar as informações necessárias, enquanto, na disciplina introdutória de Libras, aprendem-se as vivências no dia a dia.

Fazer a disciplina de Libras não foi o suficiente. Nem de perto, o suficiente. Tem algumas coisas, alguns termos, que são muito complexos, que é muito específico [...]. (AF5)

[...] com a professora (de Libras) era uma coisa e era o básico e lá (farmácia escola) eu tive que saber mais técnica, né, medicamento, com o que eu trabalho. (AFC10)

[...] eu tinha um receio porque, a gente teve Libras, mas eu vou te dizer que eu não sei, não consigo acompanhar [...] porque foi um semestre e bem mais ou menos. Não tem como tu pegar super [...] e acho que a minha maior dificuldade era passar o que eu queria para ele. (AF3)

\section{DISCUSSÃO}

O cotidiano da pessoa surda não é apenas cenário, mas expressa as cenas do viver e do conviver, mostrando-se com suas potências e seus limites. As potências referem-se à força que vem do interior de cada pessoa, sendo da ordem da libertação e da cooperação. Os limites envolvem a noção de determinação ou empenho, sendo um mecanismo de sobrevivência diante de situações cotidianas, ou seja, aquilo que protege a pessoa de determinados acontecimentos característicos da condição humana. ${ }^{15}$

Destaca-se, considerando as potências reveladas na formação para o cuidado à saúde da pessoa surda, a comunicação como alicerce para a interação entre essas pessoas e os profissionais da saúde no processo saúde-doença.

Para engendrar a integralidade do cuidado à saúde da pessoa surda, os acadêmicos utilizam a solidariedade orgânica, significando a força que vem do interior de cada pessoa, que é da ordem da comunicação instituinte, expressa pela comunicação escrita, a mímica, os gestos, o desenho e a fala pausada, que se apoia nos laços sociais afetivos, na ambiguidade básica da estruturação simbólica, garantindo a "coesão" do grupo, a troca, a partilha de valores, de lugares, de ideias, em contraponto à solidariedade mecânica, que é da ordem do instituído. ${ }^{16}$

É por meio da comunicação que se expõem o pensar e o sentir, revelando a necessidade que a pessoa tem no momento. Porém, o número de profissionais da saúde que sabem falar Libras é bem reduzido. ${ }^{17} \mathrm{Com}$ isso, os profissionais de saúde, ao não se comunicarem por meio da Libras, buscam outras possibilidades, potências para se comunicar com os usuários com surdez como, por exemplo, a escrita, os gestos ou a leitura labial. ${ }^{18}$

Para quebrar as barreiras comunicacionais, é necessário melhorar a comunicação entre o surdo e o profissional de saúde a fim de garantir uma compreensão mútua e oferecer uma assistência de qualidade. ${ }^{19} \mathrm{~A}$ Libras permite competência ao profissional de saúde para reconhecer as necessidades dessa população em sua integralidade e, assim, melhorar a relação entre o profissional e a pessoa surda. ${ }^{20}$

Devido às pessoas surdas encontrarem diariamente barreiras para se comunicar, o que as leva à exclusão social, essas pessoas trabalham para fazer acontecer a própria inclusão, a autoinclusão, esforçam-se para aprender e compreender, buscando interagir com os ouvintes. ${ }^{21}$

$O$ acadêmico, ao inserir-se no cotidiano e reconhecer as diferenças e especificidades vividas, o contorno que vem de dentro, na comunidade que atende, poderá capacitar-se e construir um novo significado aos espaços, com uma perspectiva de incentivar, na pessoa surda, o sentimento de inclusão e o reconhecimento das suas especificidades. ${ }^{22}$

É por meio das rotinas e nos costumes que se asseguram todas as formas de estar juntos; nesse discernimento, do dito comum, que permite a compreensão do ser em sua totalidade para além das determinações lógicas. ${ }^{23} \mathrm{~A}$ experiência do coletivo fundamenta a experiência individual, mesmo que conflitual, fortalecendo o grupo, trazendo a forma, os contornos de dentro, os limites e a necessidade das situações e das representações constitutivas da vida cotidiana, como fala Maffesoli. ${ }^{24}$

Em um estudo realizado com estudantes de Medicina, os motivos que os incentivaram a aprender Libras foram a curiosidade, a proximidade com a pessoa surda, seja familiar, amigo ou outros, e para romper a barreira comunicativa existente entre profissionais da saúde e as pessoas que se comunicam pela Libras. ${ }^{25} \mathrm{O}$ contato com a pessoa surda sensibiliza e potencializa a motivação de aprender Libras. ${ }^{26}$

Aprender Libras contribui para a formação do estudante, possibilitando desenvolver a capacidade crítica, reflexiva e criativa no cuidado à saúde da pessoa surda, além de nutrir a responsabilidade e o compromisso com as transformações sociais, a cidadania e a promoção da saúde, colaborando, ainda, para a construção do conhecimento.

A tecnossocialidade, ${ }^{27}$ expressada pelas TICs, é outra potência na formação dos estudantes, no cuidado à saúde da pessoa surda nos espaços da saúde, por estimular o protagonismo dessa pessoa acerca da compreensão do processo saúde-doença.

A tecnologia, como no caso dos aplicativos, promove a inclusão da pessoa com deficiência, uma vez que esta possibilita 
a melhoria da comunicação entre surdos e ouvintes, o que direciona a tecnologia a ser uma ferramenta na promoção da transformação social. ${ }^{28}$

A falta do conhecimento de Libras configura-se como um limite na formação do graduando. As barreiras na comunicação impedem o compartilhamento de informação por ambas as partes, tanto para a pessoa surda, que não consegue ser compreendida, quanto para o profissional da saúde, que não consegue dar seguimento às informações necessárias, implicando uma comunicação ineficaz, que coloca em risco a segurança da pessoa em cuidados.

O não desenvolvimento efetivo de habilidades de comunicação leva à existência de uma barreira comunicativa, dificultando o estabelecimento da relação entre o profissional e a pessoa surda, gerando frustração e infrequência da comunidade surda na assistência à saúde. ${ }^{25}$

A ausência de uma comunicação efetiva, a necessidade de intermediação pelo acompanhante e o despreparo dos profissionais são exemplos de dificuldades que direcionam ao bloqueio da comunicação, prejudicando, assim, um possível vínculo entre o profissional e a pessoa surda, que, consequentemente, compromete $o$ atendimento. ${ }^{7}$

A intermediação da comunicação entre o profissional da saúde e a pessoa surda resulta em implicações negativas, pois, a partir do momento que alguém responde pela pessoa, faz com que se torne notória a perda da sua autonomia, devido à exclusão do processo de comunicação com o profissional, o que acarreta, também, implicações éticas em relação à sua privacidade e de quebra de sigilo acerca de informações que a pessoa não deseja compartilhar. ${ }^{29}$

Os modelos e as práticas formativas atuais foram considerados, pelos acadêmicos, algo que precisa ser repensado de modo a garantir o acesso universal aos serviços de saúde, sem exclusão. Há uma necessidade emergente de incluir, nos currículos de graduação dos cursos da saúde, disciplinas obrigatórias que abordem a temática deficiência e reabilitação, considerando que $23 \%$ da população brasileira possui algum tipo de deficiência. ${ }^{2}$

Embora as pessoas com deficiência tenham a seu favor as diretrizes da Política Nacional de Saúde da Pessoa com Deficiência $^{30}$ que, em parceria com o Ministério da Educação, recomendam a inclusão de componentes curriculares nos currículos de graduação das profissões na área da saúde, os quais enfoquem a prevenção, a atenção e a reabilitação às pessoas com deficiência, o fomento de projetos de pesquisa e extensão nessa área do conhecimento, a qualificação de recursos humanos e a reorganização dos serviços, ainda se percebe a inobservância destes componentes curriculares nos currículos de graduação, configurando-se uma lacuna na formação dos estudantes.

Em tempos pós-modernos, ${ }^{31}$ busca-se o vínculo social, um justar-se ao meio, respeitando-se diferentes ritmos e identidades múltiplas. A universidade não tem que ser apenas uma escola profissional, mas, também, implementar uma visão transversal do mundo.
Os cursos da saúde necessitam melhorar o currículo acadêmico no sentido de preparar melhor os graduandos para o cuidado à saúde da pessoa surda. ${ }^{32} \mathrm{~A}$ falta de preparo de profissionais da saúde para atender a pessoa surda está relacionada com a carência de conhecimentos, poucas capacitações e ausências sobre o tema durante a formação acadêmica.

Esta lacuna de conhecimento mostra a necessidade de incluir, na grade curricular acadêmica, conteúdos relacionados ao cuidado à saúde das pessoas surdas a fim de capacitar os futuros profissionais da saúde a exercer um cuidado eficaz e com especificidades desse grupo, além de com qualidade. ${ }^{33}$

O professor tem um papel determinante para propor novos ensinamentos a seus alunos, por estar em contato diário e direto com eles, podendo incentivar o acadêmico a aprender Libras. ${ }^{34}$

A disciplina introdutória de Libras dá uma boa base inicial, apesar de insuficiente, pois não permite contemplar todos os conteúdos previstos nas ementas dos cursos de graduação. ${ }^{35} \mathrm{~A}$ disciplina de Libras no Ensino Superior, geralmente, tem uma carga horária pequena para que ocorra a efetiva aprendizagem de Libras pelos acadêmicos. ${ }^{36}$

Nesse sentido, destaca-se a importância da disciplina obrigatória de Libras nos cursos de graduação da área da saúde para que se possam diminuir as barreiras de linguagem com a pessoa surda, possibilitar falar e ser compreendido, enxergar e não apenas ver, sentir e não apenas tocar no processo saúdedoença.

\section{CONCLUSÕES E IMPLICAÇÕES PARA A PRÁTICA}

Ao compreender as potências e os limites nas atividades cotidianas da formação de estudantes de graduação no cuidado à saúde da pessoa surda nos ambientes da saúde, foi possível evidenciar que a comunicação instituinte configura-se em uma potência para os acadêmicos que, ao tentarem se comunicar, se utilizam da razão sensível por meio da escrita, da mímica, dos gestos, do desenho e da fala pausada.

Comunicar-se em Libras é uma condição essencial para a aproximação com a pessoa, conferindo a competência no cuidado $e$ a satisfação do profissional/pessoa pela possibilidade de interação e de resolução. Mesmo que a comunicação em Libras não seja fluente, a possibilidade de ser ouvido e compreendido em suas necessidades possibilita uma comunicação interpessoal mais afetiva, portanto, efetiva e empática. Nesse sentido, aprender Libras e integrar-se à comunidade surda é uma potência na formação, possibilitando o desenvolvimento da capacidade crítica, reflexiva e de compromisso social.

A tecnossocialidade, enquanto tecnologias de comunicação, é outra potência no processo comunicativo entre a pessoa surda e os profissionais da saúde por estimular o protagonismo e o autocuidado. Proporciona a inserção social e impulsiona as relações interpessoais, facilitando a aderência ao cuidado à saúde da pessoa surda. 
Quanto aos limites, observa-se que os modelos e as práticas pedagógicas atuais são insuficientes no atendimento às necessidades de acesso à saúde da pessoa surda. A comunidade surda tem seus direitos de acesso à saúde negligenciados pela falta de comunicação adequada e satisfatória nos ambientes em saúde, colocando em risco a sua segurança.

As limitações deste estudo relacionam-se às evidências específicas do grupo estudado, que pertence a uma realidade que pode diferenciar-se de outra, o que impede a generalização dos resultados. No entanto, com base nos resultados encontrados, a amostragem intencional pode ser considerada representativa em populações e condições similares.

A contribuição deste estudo consiste na possibilidade de reflexões sobre a importância de inserir os acadêmicos em projetos de pesquisa e de extensão que envolvam o cuidado à saúde da pessoa surda, favorecendo o processo comunicacional nos ambientes da saúde e o conhecimento dos termos técnicos e específicos das respectivas profissões.

\section{CONTRIBUIÇÕES DOS AUTORES}

Desenho do estudo. Lucas Andreolli Bernardo. Adriana Dutra Tholl. Soraia Dornelles Schoeller. Daniela Priscila Oliveira do Vale Tafner.

Coleta ou produção dos dados. Lucas Andreolli Bernardo. Adriana Dutra Tholl

Análise de dados. Lucas Andreolli Bernardo. Adriana Dutra Tholl. Daniela Priscila Oliveira do Vale Tafner.

Interpretação dos resultados. Lucas Andreolli Bernardo. Adriana Dutra Tholl. Daniela Priscila Oliveira do Vale Tafner. Rosane Gonçalves Nitschke. Selma Maria da Fonseca Viegas. Soraia Dornelles Schoeller. Maria Ligia dos Reis Bellaguarda.

Redação e revisão crítica do manuscrito. Lucas Andreolli Bernardo. Adriana Dutra Tholl. Rosane Gonçalves Nitschke.

Selma Maria da Fonseca Viegas. Soraia Dornelles Schoeller. Maria Ligia dos Reis Bellaguarda. Daniela Priscila Oliveira do Vale Tafner.

Aprovação da versão final do artigo. Lucas Andreolli Bernardo. Adriana Dutra Tholl. Rosane Gonçalves Nitschke. Selma Maria da Fonseca Viegas. Soraia Dornelles Schoeller. Maria Ligia dos Reis Bellaguarda. Daniela Priscila Oliveira do Vale Tafner.

Responsabilidade por todos os aspectos do conteúdo e a integridade do artigo publicado. Lucas Andreolli Bernardo. Adriana Dutra Tholl. Rosane Gonçalves Nitschke. Selma Maria da Fonseca Viegas. Soraia Dornelles Schoeller. Maria Ligia dos Reis Bellaguarda. Daniela Priscila Oliveira do Vale Tafner.

\section{EDITOR ASSOCIADO}

Marcelle Miranda da Silva

\section{REFERÊNCIAS}

1. Kuenburg A, Fellinger P, Fellinger J. Health care access among deaf people. J Deaf Stud Deaf Educ. 2016;1(21):1-10. http://dx.doi.org/10.1093/ deafed/env042. PMid:26405210.
2. Instituto Brasileiro de Geografia e Estatística. Censo demográfico 2010 [Internet]. Rio de Janeiro: IBGE; 2010. [citado 2020 Nov 19]. Disponível em: https://censo2010.ibge.gov.br/resultados.html

3. World Health Organization. Prevention of blindness and deafnes: estimates [Internet]. Genebra: WHO; 2018. [citado 2020 Nov 19]. Disponivel em: https://www.who.int/deafness/estimates/en/

4. Tsimpida D, Kaitelidou D, Galanis P. Determinants of health- related quality of life (HRQoL) among deaf and hard of hearing adults in Greece: a cross-sectional study. Arch Public Health. 2018;1(76):1-11. http:// dx.doi.org/10.1186/s13690-018-0304-2. PMid:30338066.

5. Lei n. 10.436 de 24 de abril de 2002 (BR). Dispõe sobre a Língua Brasileira de Sinais - Libras e dá outras providências. Presidência da República, Casa Civil. Brasília (DF), abr. 2002. Disponível em: http:// www.planalto.gov.br/ccivil_03/LEIS/2002/L10436.htm

6. Portaria n. $2.073,28$ de setembro de 2004 (BR). Institui a Política Nacional de Atenção à Saúde Auditiva. Ministério da Saúde, Brasília (DF), set.2004. Disponível em: http://bvsms.saude.gov.br/bvs/saudelegis/ gm/2004/prt2073_28_09_2004.html

7. Pires HF, Almeida MAPT. A percepção do surdo sobre o atendimento nos serviços de saúde. Rev. Enferm. Contemp. 2016;1(5):68-77. http:// dx.doi.org/10.17267/2317-3378rec.v5i1.912.

8. Boff L. Saber Cuidar: Ética do humano - compaixão pela terra. Rio de Janeiro: Vozes; 1999. 84 p.

9. Devkota HR, Murray E, Kett M, Groce N. Healthcare provider's attitude towards disability and experience of women with disabilities in the use of maternal healthcare service in rural Nepal. Reprod Health. 2017;1(14):114. http://dx.doi.org/10.1186/s12978-017-0330-5. PMid:28662710.

10. Francisqueti V, Teston EF, Costa MAR, Souza VS. Sentimentos da equipe de enfermagem ao atender um paciente com deficiência auditiva: Desafios do cuidado. REAI. 2017;3(13):31-51. http://dx.doi.org/10.59 65/1984317813032017031.

11. Nitschke RG, Tholl AD, Potrich T, Silva KM, Michelin SR, Laureano DD Contribuições do pensamento de Michel Maffesoli para pesquisa em enfermagem e saúde. Texto Contexto Enferm. 2017;4(26):1-12. http:// dx.doi.org/10.1590/0104-07072017003230017.

12. Maffesoli M. O tesouro escondido: carta aberta aos franco-maçons e a outros. Porto Alegre: Sulina; 2019. 191 p

13. Vinuto J. Amostragem em bola de neve na pesquisa qualitativa: um debate em aberto. Temáticas. 2014;44(22):203-20. http://dx.doi. org/10.20396/temáticas.v22i44.10977.

14. Bardin L. Análise de Conteúdo. Lisboa: Edições 70; 2011

15. Maffesoli M. O conhecimento comum: compêndio de sociologia compreensiva. Tradução de Aluizo Ramos Trinta. Porto Alegre: Sulina 2010.

16. Maffesoli M. A conquista do presente. Rio de Janeiro: Rocco; $1984.17 \mathrm{p}$.

17. Oliveira ECP, Andrade EGS. Comunicação do profissional de enfermagem com o deficiente [Internet]. Rev. Cient. Sena Aires. 2016 [citado 2020 Nov 19] 5(1):30-38. Disponível em: http://revistafacesa.senaaires.com. br/index.php/revisa/article/view/253

18. Soares IP, Lima EMM, Santos ACM, Ferreira CB. Como eu falo com você? A comunicação do enfermeiro com o usuário surdo. Rev. Baiana Enferm. 2018;10(32):1-8. http://dx.doi.org/10.18471/rbe.v32.25978.

19. Lunza S, Emma N. Experiences of registered nurses on communication with deaf patients at Katurata state hospital, Namibia. Int. J. Med. 2017 5(1):82-86. https://doi.org/doi:10.14419/ijm.v5i1.7301

20. Cavagna VM, Silva WPJ, Braga LS, Andrade M. O paciente surdo e suas vivências no sistema de saúde: uma interface com a enfermagem. Enferm. Atual. 2017;18(80):33-9. http://dx.doi.org/10.31011/reaid-2017v.80-n.18-art.345.

21. Sanches IR, Silva PB. A inclusão de estudantes surdos no ensino superior brasileiro: O caso de um curso de Pedagogia. Rev Port Educ. 2019;1(32):155-72. http://dx.doi.org/10.21814/rpe.14955.

22. Marques RS, Pereira RMP. Acessibilidade dos surdos: formação dos profissionais de enfermagem em Itubiara/GO. Revista Vale. 2017 5(9):161-172.

23. Maffesoli M. A palavra do silêncio. São Paulo: Palas Athenas; 2019 
24. Maffesoli M. A ordem das coisas: pensar a pós-modernidade. Rio de Janeiro: Forense Universitária; 2016

25. Dias AR, Coutinho CR, Gaspar DR, Moeller L, Mamede M. Libras na formação médica: possibilidade de quebra da barreira comunicativa e melhora na relação médico-paciente surdo. Rev Med (São Paulo). 2017;4(96):209-2014. http://dx.doi.org/10.11606/issn.1679-9836. v96i4p209-214.

26. Silva CNN, Gomes KVV. A relação surdo/ouvinte e seu impacto na inclusão de estudantes surdos: um estudo a partir da percepção dos intérpretes de Libras. Rev Educ. 2018;3(14):60-81.

27. Maffesoli M. Pactos emocionais: reflexões em torno da moral, da ética e da deontologia. Curitiba: PUCPRESS; 2018. 80 p.

28. Oliveira ES, Lopes KFO, França NM, Santos EF, Alvarenga MA. A utilização do aplicativo Hand Talk como ferramenta de apoio aos professores de ciências na educação inclusiva. RInTE. 2019; 1(5):1-14.

29. França EG. Dificuldades de profissionais na atenção à saúde da pessoa com surdez severa. Cienc. Enferm. 2016;22(3):107-16. http://dx.doi. org/10.4067/S0717-95532016000300107.

30. Portaria n. 1.060 de 5 de abril de 2002 (BR). Política Nacional da Pessoa com Deficiência. Diário Oficial da União [periódico na internet] Brasília (DF), 2010 [citado 2020 Nov 19] Disponível em: http://bvsms.saude. gov.br/bvs/saudelegis/gm/2002/prt1060_05_06_2002.html
31. Maffesoli M. Quem é Michel Maffesoli: Entrevistas com Christophe Bourseiller. Rio de Janeiro: Mauad; 2011.

32. Rocha CAS, Carvalho SAS, Roberto ACF, Oliveira EMP, Melo IM, Guerra LB. Formação de profissionais da saúde e acessibilidade do surdo ao atendimento em saúde: contribuições do projeto "Comunica". Revista Eletrôn. de Extensão. 2017; 1(5):112-128. https://www.researchgate. net/publication/321906264_Formacao_de_profissionais_da_saude_e_ acessibilidade_do_surdo_ao_atendimento_em_saude_contribuicoes_ do_projeto_Comunica

33. Bornholdt L. Cuidados de enfermagem a indivíduos com surdez e/ou mudez em instituição hospitalar. REAID. 2019;88(27):1-7. http://dx.doi. org/10.31011/reaid-2019-v.89-n.27-art.422.

34. Souza RS, Amoedo FKF, Azevedo MJS. Aprendendo Libras no contexto das escolas do campo no município de Parintins - AM. Revista em Extensão. 2019; 8(5):66-74. http://periodicos.uea.edu.br/index.php/ extensaoemrevista/article/view/597/579

35. Santos CAC. Licenciatura em educação do campo: a percepção de universitários sobre a disciplina de Libras. Revista Sinalizar. 2019;1(4):1 14. http://dx.doi.org/10.5216/rs.v4.56161.

36. Dalsico AMP. A disciplina de Libras no contexto da EaD. Rev. Dia. 2016 1(4):79-89. https://periodicoscientificos.ufmt.br/ojs/index.php/revdia/ article/view/3898

a Artigo extraído do trabalho de conclusão de curso "O QUOTIDIANO DA FORMAÇÃO DE ESTUDANTES DE GRADUAÇÃO PARA O CUIDADO À PESSOA SURDA: POTÊNCIAS E LIMITES", de autoria de Lucas Andreolli Bernardo, orientado por Dra. Adriana Dutra Tholl, apresentado no ano de 2020 , ao curso de graduação em enfermagem da Universidade Federal de Santa Catarina. 